\title{
Linfoma no Hodgkin y aparato urinario. A propósito de un caso
}

\author{
F. Martín Laborda y Bergasa, D. Lozano Lozano, J.J. Gil Fernández, R. Serrado Pardo, \\ J.M. Fernández Rañada
}

Unidad de Urología. Clínica La Luz. Madrid

Actas Urol Esp 2005; 29 (4): 427-432

\section{RESUMEN}

\section{LINFOMA NO HODGKIN Y APARATO URINARIO. A PROPÓSITO DE UN CASO}

Describimos un caso de linfoma secundario no Hodgkin con presentación metacrónica en vejiga y riñón izquierdo, en un paciente con diferentes afectaciones extragonadales. Tanto en la vejiga como en el riñón se trataba de un linfoma de bajo grado tipo B de células centrofoliculares.

Se sugiere la diseminación hematógena y afinidad del clon linfomatoso por el aparato urinario.

Se establecen algunas consideraciones diagnósticas, así como sobre el enfoque terapéutico en este tipo de patologías.

Palabras clave: Linfoma no Hodgkin. Linfoma de células B, Linfoma urológico, Cáncer genito-urinario.

\section{ABSTRACT}

\section{NON-HODGKIN'S LYMPHOMA AND URINARY TRACT. ABOUT A CASE REPORTED}

We pass to describe a case of non Hodgkin's secondary lymphoma with metachronic affectation in bladder and left kidney, in a patient with different extranodals locations. Both in bladder and kidney, it was a low grade lymphoma type B with centrofolicular cells.

We suggest haematogenous dissemination and affinity of lymphomatous clone to the urinary tract.

We establish some diagnostic considerations, such about the therapeutic management in this type of pathologies.

Keywords: Non-Hodgkin's lymphoma. B-Cell Lymphoma. Urological lymphoma. Genitourinary cancer.

$\mathrm{L}$ os linfomas malignos componen un grupo de enfermedades, cuyo origen procede de los ganglios linfáticos o del tejido linfoide de diferentes órganos parenquimatosos.

Los órganos del aparato genito-urinario se encuentran afectados en el linfoma maligno en el $50 \%$ de las necropsias realizadas, en los pacientes que padecen este tipo de patologías.

Sin embargo en la clínica los linfomas no Hodgkin son poco habituales en el aparato urinario, sólo se demuestran en el 10\% de los casos diagnosticados y sólo se comprueban como procesos primarios en un $1 \%$.

Describimos un caso de linfoma no Hodgkin tipo B de células centrofoliculares, con afectación metacrónica primero en la vejiga y tres años y medio más tarde en el riñón derecho, en un paciente que previamente había sido sometido a la extirpación de una tumoración de similar histopatología que afectaba a la grasa retroocular.

\section{CASO CLÍNICO}

Varón de 70 años de edad con antecedentes de resección endoscópica de la próstata hace diez años comprobando una HBP.

Aquejado de exoftalmos izquierdo en julio de 1995, fue sometido a la extirpación quirúrgica de un tumor que afectaba a la grasa retro-ocular izquierda seguida de irradiación local a dicho nivel; diagnosticado como afectación primaria de linfoma retro-ocular no Hodgkin con bajo grado de malignidad de células B y sugestivo de ser un linfoma centrofolicular. 
En febrero de 1998 presentó recidiva ganglionar con afectación no voluminosa a nivel supraclavicular y de mediastino con histología de linfoma B de bajo grado que siguió un curso clínico indolente sin precisar tratamiento.

En marzo de 2000 fue diagnosticado en una TAC de control de una formación de aspecto nodular de $1,5 \mathrm{~cm}$ la pared vesical izquierda. Intervenido mediante resección endoscópica de dicha tumoración sólida de vejiga, que se demostró infiltraba la lámina propia respetando el urotelio de revestimiento. La histologia fue de linfoma no Hodgkin de bajo grado con células $\mathrm{B}$ y un patrón de crecimiento nodular de probable origen centrofolicular (en el estudio inmuno-histoquímico se observó una fuerte positividad de la celularidad neoplásica con anticuerpo CD20, así como positividad de las zonas centrofoliculares con bcl-2 y CD10). Los marcadores de célula $\mathrm{T}$ fueron negativos. El diagnóstico definitivo fue de linfoma no Hodgkin de tipo folicular Gr. I (clasificación OMS). Posteriormente siguió un tratamiento con Clorambucil y Prednisona que se mantuvo hasta abril de 2001.

En diciembre de 2003, en una TAC abdominopélvica incluida en controles habituales, se detectó en el riñón derecho una lesión nodular hipoecogénica de $4 \mathrm{~cm}$. de diámetro con estructura homogénea y aspecto sólido (Fig. 1). Se realizó la tumorectomía de una neoplasia bien encapsulada con biopsia de la grasa perirenal adyacente. La anatomía patológica fue similar a la ya obtenida en la vejiga y confirmó se trataba de una neoplasia linfoide maligna no Hodgkin de bajo grado

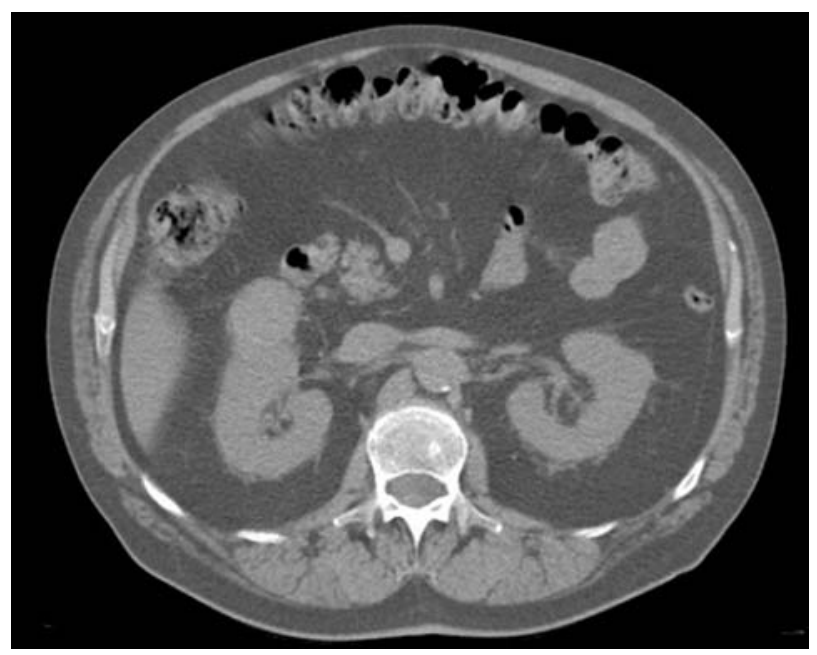

FIGURA 1. TAC abdómino-pélvico. de células $\mathrm{B}$, con afectación intersticial de la corteza renal, que infiltraba la grasa perirenal y estaba constituida por células de pequeño tamaño que se disponían formando estructuras foliculares; el perfil inmuno-histoquímico fue compatible con un linfoma de células centrofoliculares tipo I.

Tanto en la vejiga como en el riñón la proliferación neoplásica tenía habito linfoide y mostraba un patrón folicular con folículos neoplásicos adosados entre sí, mal definidos, sin zona del manto y de diámetros heterogéneos. Las células linfoides que los constituían eran de tipo centrocito, de pequeño tamaño, con núcleo irregular y escaso citoplasma y se entremezclaban con una población escasa de células centroblásticas, de mayor tamaño y núcleos vesiculosos. No se observaron áreas difusas ni de alto grado (Figs. 2 y 3 ).

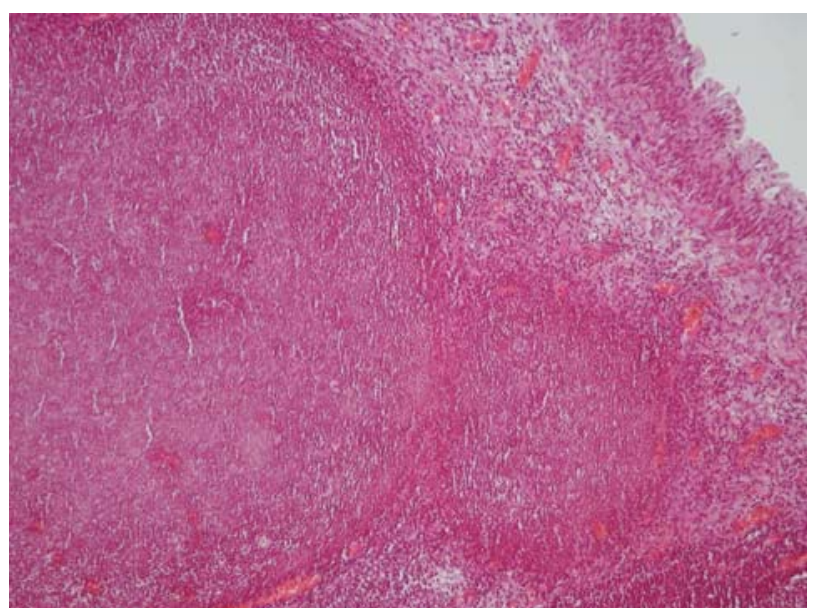

FIGURA 2. Pared vesical.

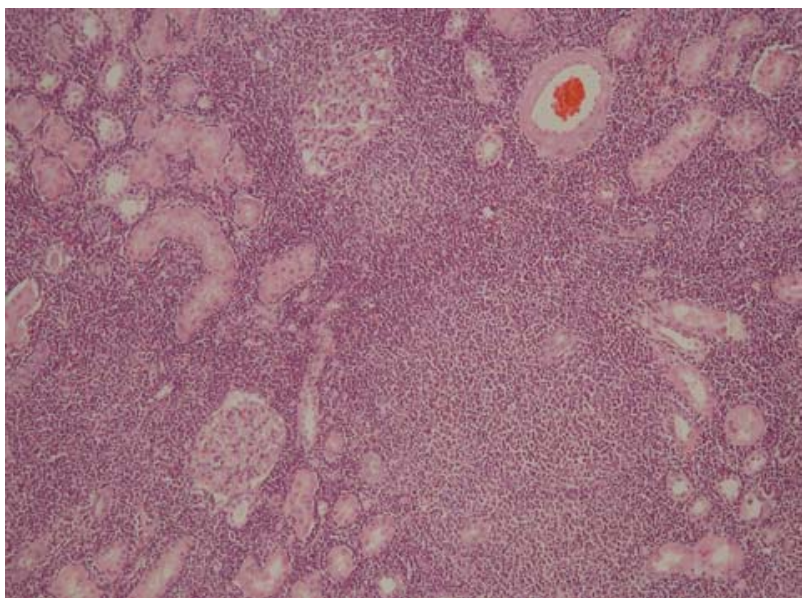

FIGURA 3. Parénquima renal. 


\section{DISCUSIÓN}

A pesar de que existen muchos trabajos publicados en los últimos años sobre los linfomas malignos primarios que se localizan en diversos órganos del aparato urinario, con referencia al riñón, vejiga y testículo de manera preferente, no se ha prestado tanto interés a los linfomas malignos de otro origen que metastatizan en las vísceras del aparato urinario.

Existen clasificaciones basadas en el patrón de crecimiento, ya sea nodular o difuso, en el tamaño celular y en otras características del núcleo de la célula maligna. La más antigua es de la de Rappaport de 1966, modificada por otros autores como Lukes y Collins en función de que las células originales sean linfocitos B, T o histiocitos.

Desde el punto de vista pronóstico se ha confirmado la importancia que tiene la valoración histológica de los linfomas por su arquitectura en nodulares y difusos, al margen del tipo celular observado $^{1}$. Kiel introdujo la correlación de la línea inmunológica y el estadio funcional con la apariencia morfológica ${ }^{1-3}$.

En cuanto a la epidemiología los linfomas suelen afectar al aparato urinario en las edades medio-avanzadas de la vida, con predominio en los varones en la mayoría de las series ${ }^{4}$. En los últimos años se ha descrito una mayor incidencia de las neoplasias linfoides en los pacientes afectos por SIDA y en los transplantados, como consecuencia de su inmunodeficiencia ${ }^{5,6}$.

Se ha demostrado que alrededor del 30 al 50 por ciento de los pacientes con linfoma maligno presentan afectación renal en la autopsia, no así en la clínica en la que sólo se comprueba el linfoma secundario en riñón en el $5 \%$ de los casos (como tumor primario en el aparato urinario sólo se presenta en el $1 \%$ ).

Las metástasis del linfoma no Hodgkin (LNH) son mucho más frecuentes que las del linfoma de Hodgkin. Por otro lado la relación entre el grado histológico y la frecuencia de las metástasis no ha sido demostrada ${ }^{6-9}$.

En general cuando se comprueba que los órganos del aparato urinario están afectados, podemos hablar de que la enfermedad se ha diseminado ${ }^{8}$.

El riñón es el órgano en que la diseminación linfomatosa es más frecuente excluyendo los sis- temas hematopoyético y retículo-endotelial ${ }^{6}$. Sin embargo a pesar de que la infiltración renal por linfoma es común, el linfoma renal localizado es muy raro y sólo supone un $0,5 \%$ de los tumores renales en general $^{8}$.

La invasión del riñón se produce bien por vía hematógena bien por contigüidad a través del retroperitoneo. Al principio las células tumorales se localizarían en el espacio intersticial respetando los vasos y la estructura nefronal, mas tarde al hacerse el tumor expansivo destruiría las estructuras adyacentes ${ }^{7}$.

Se ha especulado sobre un posible origen de la neoplasia a partir de los ganglios del seno renal o de la red linfática de la cápsula renal con una posterior invasión del parénquima renal a través de unas, a modo de cadenas de células ${ }^{4}$.

Horii, clasifica los LNH renales en tres tipos, en función de la diseminación de esta patología:

Tipo I: Linfoma renal primario que afectaría sólo al riñón.

Tipo II: Linfoma renal más masa linfomatosa dispersa.

Tipo III: Afectación renal global (uno o dos riñones) con extensión retroperitoneal en forma de adenopatías o masas ${ }^{10}$.

En cuanto a los tumores vesicales en su mayor parte son de origen epitelial, los tumores no epiteliales los más frecuentes son el rabdomiosarcoma en los niños y el leiomiosarcoma en el adulto ${ }^{11}$. El linfoma vesical se puede clasificar como primario, no localizado y secundario. Tumores primarios son aquellos que afectan a la vejiga sin que exista ninguna otra localización demostrable, incluyendo el sistema linfático, médula ósea o sangre periférica. No localizado es aquel que se diagnostica en primer lugar en la vejiga como primera manifestación de una enfermedad diseminada. Secundarios serían aquellos casos de metástasis vesical en un paciente con historia conocida de linfoma maligno sistémico $^{12}$.

La afectación primaria de la vejiga urinaria sólo se presenta en el 1\% de los casos de linfoma, su forma más común de presentación es de linfoma no Hodgkin con "mucosa-associated lymphoid tissue" (MALT), mas común en la mujer de mediana edad que ha sufrido cistitis reiteradas. 
La malignización podría afectar a los linfocitos acumulados en la submucosa como consecuencia de la posible respuesta inmuno-inflamatoria ${ }^{11}$.

La localización secundaria es más frecuente $(17,2 \%)$ y sólo ocurre en los estadios avanzados de la enfermedad, produciendo en ocasiones uropatía obstructiva por compresión extrínseca de la vía urinaria cuando se localizan en el trígono o bien existen paquetes adenopáticos en la pelvis menor $^{2,13}$.

La clínica de la afectación renal en el LNH es inespecífica, ya sea primario o secundario: dolor abdominal impreciso, pérdida de peso, fiebre y sudoración nocturna, anemia y hematuria ${ }^{6}$. Desde la instauración de la ecografía abdominal como prueba diagnóstica de primera línea, en un alto porcentaje el diagnóstico es incidental. En los pacientes con procesos linfomatosos renales evolucionados se puede presentar insuficiencia renal favorecida no sólo por la uropatía obstructiva y posible infección urinaria, sino también por la toxicidad añadida por la quimioterapia, antibióticos y la nefropatía úrica aguda provocada por lisis tumoral ${ }^{14}$.

En el linfoma vesical la clínica es superponible a las cistopatías crónicas en cuanto a la presencia de los clásicos síntomas irritativos y a la clínica de los tumores vesicales con la hematuria como principal indicio.

El diagnóstico del LNH en el riñón se realiza de manera fundamental mediante las pruebas de imagen. La ecografía demuestra un patrón de áreas hipo o anecoicas uniforme con márgenes bien definidos. En la urografia intravenosa podrá apreciarse la modificación de los contornos renales o la distorsión de las estructuras calicilares con o sin signos de uropatía obstructiva, según la naturaleza o diseminación de las masas tumorales.

La apariencia en la TAC es la de una o múltiples lesiones sólidas con un coeficiente de absorción de baja densidad con posible infiltración o contigüidad a masas retroperitoneales en el $25 \%$ de los $\operatorname{casos}^{7}$. La RNM no ha demostrado ventajas diagnósticas en su utilización y la arteriografía renal sólo en algunos casos podría orientar en el diagnóstico diferencial con otros tumores renales más comunes ${ }^{6}$.
La arteriografía suele comprobar tumores poco vascularizados con rara afectación vascular intraluminal ${ }^{4,6}$. Algunos autores no consideran necesaria la arteriografía una vez realizada la ecografía y la $\mathrm{TAC}^{9}$.

La PAAF que puede ser útil en algunos casos en que se duda entre linfoma o adenocarcinoma renal, no permite obtener suficiente tejido para conseguir una adecuada individualización del proceso. Sólo una generosa biopsia escisional será capaz de establecer un diagnóstico diferencial de este tipo de tumores con los sarcomas y algunos casos de fibrosis retroperitoneal ${ }^{6,15}$.

Para diagnosticar el linfoma vesical aparte de todas las técnicas de imagen ya comentadas al hablar de los tumores renales hay que citar la cistoscopia con biopsia transuretral más o menos agresiva según las indicaciones en cada caso concreto.

En cuanto a estadiaje sólo se podrá considerar completo una vez realizada la exploración clínica, análisis de sangre, radiografias de tórax, TAC pulmonar y abdomino-pélvico y biopsia de médula ósea. Sólo un linfoma podrá ser considerado primario cuando todas estas técnicas sean negativas $^{11}$.

El estudio histológico y las técnicas inmunohistoquímicas son la pruebas que confirman el LNH, de esta manera en el caso de los tumores vesicales obtendremos marcadores para células linfoides en el caso del linfoma o para células epiteliales en el caso del carcinoma. Para el diagnóstico diferencial en los casos de cistopatías de larga evolución con piuria, se ha valorado como alternativa la inmuno-citología ${ }^{16}$.

En lo que se refiere al tratamiento, lo primero que hay que considerar es el grado de extensión de la enfermedad. Estadio I cuando se encuentra confinada a un único lugar anatómico o a un grupo ganglionar. Estadio II Linfoma confinado a una región anatómica a un lado del diafragma. Estadio III cuando existen adenopatías a ambos lados del diafragma. Estadio IV, aquel en que existe diseminación parenquimatosa.

El pronóstico de los linfomas diseminados no es peor que el de las formas localizadas, como consecuencia del uso de la poli-quimioterapia de mayor agresividad, curativa en el 40 a $50 \%$ de los pacientes. 
La cirugía para estos tumores no puede considerarse nunca curativa, y su papel debe considerarse diagnóstico con el objetivo de establecer un tratamiento paliativo con la menor morbilidad posible, La radioterapia tendrá un papel exclusivo en las formas localizadas ${ }^{16}$.

Dado el hecho de que la mayoría de los casos que se diagnostican en urología son estadios III o IV. El tratamiento de elección es la quimioterapia sistémica. Así Withmore diseñó un tratamiento intensivo durante treinta semanas con ciclos intermitentes de Bleomicina, Ciclofosfamida, Vincristina y Dexametasona con altas dosis de metotrexato. Obtiene remisiones completas en el 78\% de los casos que se mantienen durante dos años en $80 \%$ de los pacientes tratados. Aunque la alternativa de tratamiento quimioterápico habitual parece ser la pauta CHOP (hasta nueve ciclos con Ciclofosfamida, Doxorubicina, Vincristina y Prednisolona), existen pautas alternativas como la VIM-Bleo que asocia Iofosfamida, Metotrexate, Etoposido y Bleomicina $^{17}$.

En algunos casos de linfomas evolucionados se administró quimioterapia en dosis altas, seguida de auto-transplante de médula con buenos resultados en los periodos de supervivencia libres de enfermedad ${ }^{6}$.

En el tratamiento del LNH primario de vejiga se han comprobado buenos resultados con la cistectomía parcial (endoscópica o mediante cirugía abierta) o total asociada a radioterapia ${ }^{13}$. Sin embargo algunos autores desaconsejan la cirugía radical $^{11}$. En los tumores vesicales de carácter metastático, la actitud inicial se limitaría a la biopsia acompañada de técnicas quirúrgicas desobstructivas, en los casos que lo precisen, combinadas con la quimioterapia como fundamental recurso terapéutico ${ }^{18}$.

En el linfoma renal también la cirugía deberá interpretarse como diagnóstica, evitando la cirugía de exéresis radical que condicionaría la función renal y el posible tratamiento con una dosificación quimioterápica eficaz.

\section{CONCLUSIONES}

Los linfomas malignos son una patología relativamente frecuente (séptima causa más común de muerte por cáncer en USA), favorecida hoy por la inmunodeficiencia propia de los transplantes y SIDA.
Los linfomas primarios que afectan a los órganos del aparato urinario constituyen una patología extremadamente rara, no así los linfomas secundarios más frecuentes en la evolución sistémica de esta enfermedad.

La afectación metacrónica en vejiga urinaria y años más tarde en riñón derecho, de un linfoma no Hodgkin tipo B de células centro foliculares, como órganos no contiguos del aparato urinario, sugiere la importancia en esta enfermedad de la diseminación hematógena.

El tratamiento de exéresis local, sólo está justificado para obtener una mayor seguridad en el diagnóstico histológico. El procedimiento quirúrgico debe ser poco invasivo y de intención paliativa, para evitar una mayor morbilidad y en el caso de afectación renal para preservar la función renal.

La radioterapia sólo tendría interés en el tumor localizado y órgano confinado, sola o adyuvante a la cirugía no agresiva. La remisión clinica únicamente se consigue con un tratamiento con poli-quimioterapia.

Aunque el mejor pronóstico conceptualmente es el de los tumores localizados, la remisión clínica sólo se obtendrá en los casos correctamente tratados.

\section{REFERENCIAS}

1. The Non-Hodgkin's Lymphoma Pathologic Classification Project: National Cancer Institute sponsored study of classification of non Hodgkin's lymphomas: summary and description of a working formulation for clinical usage. Cancer 1982;49:2112-2135.

2. Amat Cecilia M, Romero Perez P, Sevilla Chica FI: Linfomas del tracto genitourinario. Revisión de conjunto y aportación de dos casos de localización testicular. Arch Esp Urol 1994; 47:992-997.

3. Begara Morillas A, Silmi Moyano A, Hermida Gutérrez J, Chicharro J, Férnández M.J. Martín C, Ramírez JC, Rapariz M, Salinas J, Resel L Patología linfoproliferativa del tracto genitourinario. Aportación de 6 casos y revisión de la literatura. Arch Esp Urol 1996;49:562-570.

4. Torrecilla García-Ripoll JR, Pascual Samaniego M, Martín Blanco S, Rivera Ferro J, Peral Martínez JI, Fernández Del Busto E. Linfoma renal primario. Actas Urol Esp 2003;27: 555-558.

5. García Freire C, Busto Castanon L, Pombo Felipe F y cols. Linfoma renal primario en paciente V.I.H. positivo. Arch Esp Urol 1994;47:287-289.

6. Salem Y, Miller HC. Lymphoma of genitourinary tract. J Urol 1994;151:1162-1170.

7. Cohan RH, Reed Dunnick N, Leder A, Baker E. Computed Tomography of Renal Lymphoma. J Comput Assist Tomogr 1990; 14:933-938. 
8. Lewi HJ, Stewart ID, Seywright M, Fleming S, Deane RF, Kyle KF. Urinary tract lymphoma. Br J Urol 1986;58(1):1618.

9. Miyake O, Namiki M, Sonoda T, Kitamura H: Secondary involvement of genitourinary organs in malignant lymphoma. Urol Int 1987;42:360-362.

10. Horii SC, Bosniak MA, Megibow AJ, Raghavendra BN, Subramanyam BR, Rothberg M. Correlation of CT and Ultrasound in the evaluation of renal lymphoma. Urol Radiol 1983;5(2):69-76.

11. Wazait HD, Chahal R, Sundurum SK, Rajkumar GN, Wright D, Aslam MM. MALT-type primary lymphoma of the urinary bladder: clinicopathological study of 2 cases and review of the literature. Urol Int 2001;66(4):220-224.

12. Kempton CL, Kurtin PJ, Inwards DJ, Wollan P, Bostwick DG. Malignant Lymphoma of the bladder: Evidence from 36 cases that low-grade lymphoma of the MALT-type is the most common primary bladder lymphoma. Am J Surg Pathol 1997;21(11):1324-1333.

13. Rodríguez Martín F, Fernández Fernández A, Gil Paraiso y cols. Linfoma vesical de localización retrotrigonal. Actas Urol Esp 1996;20:900-903.
14. RODRIGUEZ JA, GARMENDIA JC, HERNANDEZ I y cols. Linfoma y aparato genitourinario: a propósito de un caso. Arch Esp Urol 1990;43:1023-1025.

15. Whitmore Wf, Skarin At, Rosenthal Ds. Urological presentations of non-Hodgkin's lymphomas. J Urol 1982;128:953-956.

16. Froehner M, Haase M, Hakenberg Ow, Wirth Mp: Urinary immunocytology for primary bladder B cell lymphoma. Urology 2004;63:381-383.

17. Steinke B, Kruger HU, Kraft H, Heim ME, Gunther E, Arnold $\mathrm{H}$, Busch FW. Response-oriented therapy with CHOP and VIM-Bleo in high-grade malignant non-Hodgkin's lymphomas. Blut 1988;56(6):269-271.

18. Vesa Llanes J, Bielsa Gali O, Llado Carbonell C, Arango Toro O, Barranco C, Gelabert i Mas A. Afectación vesical por linfoma no Hodgkiniano diagnóstico y respuesta terapéutica. Actas Urol Esp 1992;16(2):162-165.

Dr. F. Martín-Laborda y Bergasa

Añastro, 4

28033 Madrid

(Trabajo recibido el 21 de julio 2004) 